\title{
Effect of thymoquinone administration on erythrocyte fragility in diethylnitrosamine administered rats
}

\author{
Hawar Ahmad Muhammed Amin ${ }^{\mathrm{a}}$, Okan Arihan ${ }^{\mathrm{b}, *}$ and Murat Cetin Ragbetli ${ }^{\mathrm{a}}$ \\ a Department of Medical Histology and Embryology, Faculty of Medicine, Yuzuncu Yil University, \\ Van, Turkey \\ ${ }^{\mathrm{b}}$ Department of Physiology, Faculty of Medicine, Yuzuncu Yil University, Van, Turkey
}

\begin{abstract}
.
BACKGROUND: Diethylnitrosamine is a carcinogenic chemical found in food unintendedly and also in different media such as cosmetics. Nigella sativa plant has anti-tumoral, anti-inflammatory and anti-diabetic activities.

OBJECTIVE: Aim of this study is to investigate effect of thymoquinone -one of the active ingredients of Nigella sativa- on erythrocyte fragility in diethylnitrosamine administered rats.

METHODS: 28 male Wistar-albino rats were divided into four groups; Control group (Saline/5 days, i.p.), thymoquinone group ( $4 \mathrm{mg} / \mathrm{kg} / 5$ days/p.o.), diethylnitrosamine group (Saline/5 days, i.p. and diethylnitrosamine $200 \mathrm{mg} / \mathrm{kg} / \mathrm{i} . \mathrm{p}$. in two consecutive days) and diethylnitrosamine + thymoquinone group ( $4 \mathrm{mg} / \mathrm{kg} / 5$ days thymoquinone p.o. and diethylnitrosamine $200 \mathrm{mg} / \mathrm{kg} / \mathrm{i} . \mathrm{p}$. in two consecutive days). Erythrocyte fragility, hemoglobin and hematocrit counts were performed.

RESULTS: Number of erythrocytes was increased significantly $(p<0.05)$ in diethylnitrosamine administered group $\left(9.05 \times 10^{6} / \mathrm{mm}^{3}\right)$ compared to control $\left(7.44 \times 10^{6} / \mathrm{mm}^{3}\right)$ and thymoquinone $\left(7.75 \times 10^{6} / \mathrm{mm}^{3}\right)$. Hematocrit value was significantly higher in diethylnitrosamine group $(52.47 \%)$ compared to control $(44.75 \%)$ and thymoquinone groups $(46.21 \%)$ $(p<0.05)$. Hemoglobin value was higher in the diethylnitrosamine administered groups $(18.43$ and $17.63 \mathrm{~g} / \mathrm{dL}$ in diethylnitrosamine and thymoquinone + diethylnitrosamine groups respectively) compared to groups without diethylnitrosamine administration $(15.15$ and $15.87 \mathrm{~g} / \mathrm{dL}$ in control and thymoquinone groups respectively) $(p<0.05)$. Mch was found significantly higher in thymoquinone+diethylnitrosamine group $(p<0.05)$. No significant difference in erythrocyte fragility was observed among groups.

DISCUSSION AND CONCLUSION: Augmentation in erythrocyte, hemoglobin and hematocrit count due to diethylnitrosamine administration and a slight reversal due to thymoquinone administration were observed without statistical significance.
\end{abstract}

Keywords: Thymoquinone, diethylnitrosamine, erythrocyte, rat, Nigella sativa

\section{Introduction}

Diethylnitrosamine (DENA) is a hazardous chemical, found in cigarette, fried foods, cosmetic preparations and pesticides [1-3]. DENA is known for its carcinogenetic nature for a long time [4] and can cause various gastrointestinal system cancers such as esophagus [5], gastric cancers [6] as well as carcinogenesis in liver ${ }^{7}$. DENA causes hepatic cell necrosis without cirrhosis [8]. Because of its carcinogenic properties due to its liver cell proliferative property, it is preferred in animal studies to experimentally induce liver cancer [9-12]. Vesselinovitch et al. [13] administered DENA to C57BL/6Jx $\mathrm{C} 3 \mathrm{HeB} / \mathrm{FeJ} \mathrm{F} 1$ (B6C3F1) and C3HeB/FeJxA/J F1 (C3AF1) hybrid mice and observed tumors in liver,

\footnotetext{
*Corresponding author: Okan Arihan, Department of Physiology, Faculty of Medicine, Yuzuncu Yil University, Van, Turkey. Tel.: +90 5363470676; E-mail: okanarihan@gmail.com.
} 
lungs, and stomach. Among liver tumors hepatocellular carcinomas was the most abundant in their study. In addition to carcinogenic nature DENA also causes alterations in androgen sensitivity of hepatic cells in Wistar rats which alters physiological functions of liver adversely [14].

In addition to carcinogenetic effect, DENA causes elevation in serum AST, ALT, ALP, LDH and bilirubin levels. It also augments levels of oxidative stress markers such as lipid peroxidation and decreases antioxidants in Wistar albino rats [15]. DENA causes alterations in some enzymes found in serum and tissues. When liver cells are injured, several types of liver-specific enzymes, including aspartate aminotransferase (AST), alanine aminotransferase (ALT) and alkaline phospatase (ALP) elevates. Studies indicate that DENA elevates activities of these enzymes [16]. Avasilcai et al. [17] showed that the post treatment with sodium selenite increased DENA toxicity. Total bilirubin, direct bilirubin, HDL-cholesterol and iron blood levels, as well as GGT and AST activities were significantly increased. Gayathri et al. [18] observed changes in the levels of ATPases in liver and erythrocyte membranes of male Wistar rats when rats were administered with DENA ( $200 \mathrm{mg} / \mathrm{kg}$ bwt in saline). Administration of DENA ( $200 \mathrm{mg} / \mathrm{kgbw}$ ) to rats, caused significant decreases in serum albumin and tissue antioxidants such as GPx, GST, SOD, CAT and GSH [19].

Studies revealed that the haematopoietic system is also affected by DENA. Sarkar et al. [20] found red blood cell membrane damage due to administration of $200 \mathrm{mg} / \mathrm{kg}$ DENA to Sprague-Dawley rats. Another study by Gnanaraja and Prakash [21] also revealed alterations caused by DENA in hemoglobin and red blood cell count in mice.

Thymoquinone (TQ), is an active ingredient of Nigella sativa L (NS) seed which is a herbaceous plant. NS plant is used in folk medicine in different countries [22, 23]. Modern experimental studies revealed that Nigella sativa seeds have immune regulatory, anti-inflammatory, anti-tumoral and anti-bacterial properties [24]. Ekanem and Yusuf [25] investigated the effect of black seed oil (Nigella sativa oil) on parasitaemia. There were significant increases $(p<0.05)$ in the values of $\mathrm{Hb}, \mathrm{MCHC}$, PCV, RBC, WBC and platelet counts of the infected oil-treated rats in comparison with the infected untreated rats. Seeds of this plant contain volatile oils such as TQ. TQ was shown to exert protective effect against hepatocarcinogenesis [26-31]. Anti-proliferative and pro-apoptotic activities of TQ in both NSCLC and SCLC cell line were shown [32]. Earlier studies reported that thymoquinone exerted inhibitory effect on cell proliferation of many kinds of cancer cell lines, including breast adenocarcinoma, ovarian adenocarcinoma, colorectal cancer, human pancreatic adenocarcinoma, uterine sarcoma, neoplastic keratinocytes, human osteosarcoma, fibrosarcoma and lung carcinoma [33]. Nithya et al. [34] revealed that the oral administration of TQ at a dose of $20 \mathrm{mg} / \mathrm{kg}$ bw ameliorated levels of biochemical parameters in benzo(A)pyrene induced lung carcinogenesis in male Swiss-albino mice. TQ significantly increased the survival against LPS challenge in D-galactosamine sensitized mice, and decreased the levels of serum ALT and AST.

Aim of this study is to investigate effect of thymoquinone which is one of the active ingredients of NS on erythrocyte fragility and some selected hematological parameters in diethylnitrosamine administered rats.

\section{Materials and methods}

\subsection{Animals}

28 male Wistar-albino rats (250-300 g) were divided into four groups; Control group (Saline/5 days, i.p.), TQ group (4 mg/kg/5 days/p.o.), DENA group (SF/5 days/i.p. and DENA $200 \mathrm{mg} / \mathrm{kg} /$ i.p. in two consecutive days following 5 days of saline administration) and DENA + TQ group (4 mg/kg/5 days TQ p.o. and DENA $200 \mathrm{mg} / \mathrm{kg} / \mathrm{i} . \mathrm{p}$. in two consecutive days following 5 days of saline 
administration). Animals were kept in constant heat and humidity conditions with 12 hours of light/darkness periods. Food and water were given ad libitum except TQ group in which animals received tap water containing TQ.

Permission from Yuzuncu Yil University Ethical Commission for Animal Studies was obtained with number 2016-5171.

\subsection{Hematological measurements}

Blood was withdrawn from rats into EDTA containing tubes under anesthesia. Hemoglobin, hematocrit and red blood cell count was performed via a coulter counter device adjusted for animal research. Red Blood Cell value is presented as $x 10^{6} / \mathrm{mm}^{3}$. Hematocrit value is presented as \%. Hemoglobin value was presented as g/dL. From those measurements mean corpuscular volume (Mcv), mean corpuscular hemoglobin (Mch) and mean corpuscular hemoglobin concentration (Mchc) were also assessed.

\subsection{Erythrocyte fragility test}

Erythrocyte osmotic fragility test was performed using phosphate buffer containing dilutions from 0.1 to $0.2,0.3,0.4,0.5,0.6,0.7,0.8$ and $0.9 \%$ of $\mathrm{NaCl}$. Following 24 hours of incubation at $37 \mathrm{C}$ temperature 30 microliters of blood was added into those dilution tubes. Following gently mixing, 30 minutes of incubation at room temperature was waited. Tubes were centrifuged at $3000 \mathrm{rpm}$ for 5 minutes. Supernatant fraction of the centrifuged tubes was measured at 546 adsorbance with the aid of spectrophotometer.

\subsection{Statistical analysis}

Results are presented as arithmetic mean \pm standard error of mean. Kruskal-Wallis and Tukey's tests were performed for statistical analysis.

\section{Results}

Number of red blood cells was increased in DENA administered group $\left(9.05 \times 10^{6} / \mathrm{mm}^{3}\right)$ compared to control $\left(7.44 \times 10^{6} / \mathrm{mm}^{3}\right)$, TQ $\left(7.75 \times 10^{6} / \mathrm{mm}^{3}\right)$ TQ+DENA groups $\left(8.32 \times 10^{6} / \mathrm{mm}^{3}\right)$. This increase was significant when compared to control and TQ $(p<0.05)$ (Table 1).

Table 1

Results of hematological parameters of groups

\begin{tabular}{lcccc}
\hline & Control & TQ & DENA & TQ+DENA \\
\hline RBC $\left(10^{6} \times \mathrm{mm}^{3}\right)$ & $7.44 \pm 0.48^{\mathrm{c}}$ & $7.75 \pm 0.47^{\mathrm{bc}}$ & $9.05 \pm 0.53^{\mathrm{a}}$ & $8.32 \pm 0.51^{\mathrm{ab}}$ \\
HGB $(\mathrm{g} / \mathrm{dL})$ & $15.15 \pm 0.84^{\mathrm{b}}$ & $15.87 \pm 0.87^{\mathrm{b}}$ & $18.43 \pm 1.30^{\mathrm{a}}$ & $17.63 \pm 0.95^{\mathrm{a}}$ \\
HCT $(\%)$ & $44.75 \pm 3.20^{\mathrm{b}}$ & $46.21 \pm 2.61^{\mathrm{b}}$ & $52.47 \pm 4.99^{\mathrm{a}}$ & $49.97 \pm 3.32^{\mathrm{ab}}$ \\
Mcv (fl) & $60.10 \pm 1.48$ & $59.61 \pm 0.59$ & $57.87 \pm 2.14$ & $60.03 \pm 3.32$ \\
Mch (pg) & $20.37 \pm 0.59^{\mathrm{b}}$ & $20.50 \pm 0.58^{\mathrm{b}}$ & $20.37 \pm 0.72^{\mathrm{b}}$ & $21.23 \pm 1.36^{\mathrm{a}}$ \\
Mchc (g/dL) & $33.90 \pm 1.37^{\mathrm{b}}$ & $34.40 \pm 0.64$ & $35.27 \pm 1.04$ & $35.37 \pm 0.47$ \\
\hline
\end{tabular}

TQ: Thymoquinone, DENA: Diethylnitrosamine, TQ+DENA: Thymoquinone+Dena. $n=7$ rats for each group. Results were presented as mean \pm standard error of mean. Significant difference is accepted as $p<0.05$. Homogenous subsets are given as $\mathrm{a}, \mathrm{b}, \mathrm{c}$. 


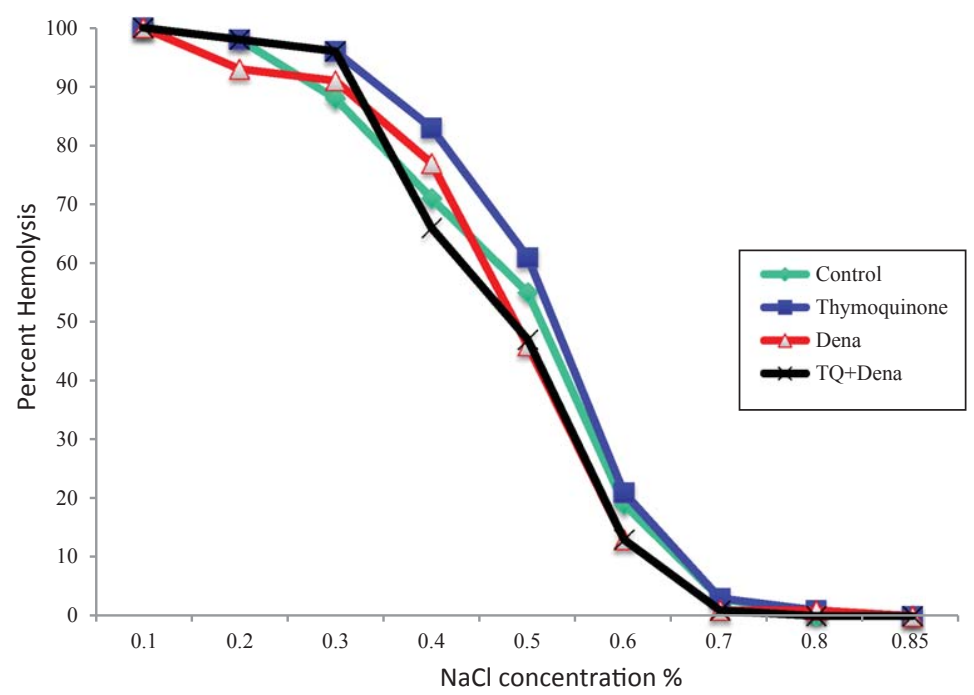

Fig. 1. Effect of Thymoquinone, DENA and TQ+DENA on erythrocyte osmotic fragility. DENA: Diethylnitrosamine, TQ+DENA: Thymoquinone+Diethylnitrosamine. Data were analyzed with Kruskal-wallis and Tukey tests. Values are presented in percent hemolysis.

Hematocrit value was found higher in DENA group (52.47\%) compared to other groups and this increase was significant compared to control $(44.75 \%)$ and TQ $(46.21 \%)(p<0.05)$ (Table 1).

Hemoglobin value was found higher in DENA $(18.43 \mathrm{~g} / \mathrm{dL})$ and TQ+DENA $(17.63 \mathrm{~g} / \mathrm{dL})$ groups compared to control $(15.15 \mathrm{~g} / \mathrm{dL})$ and TQ $(15.87 \mathrm{~g} / \mathrm{dL})$ groups $(p<0.05)$ (Table 1$)$.

In Mcv parameter DENA group was found lowest $(57.87 \mathrm{fl})$ whereas control was highest (60.10 fl) without statistical significance.

In Mch, TQ+DENA group was significantly higher (21.23 pg) compared to all other groups. Finally in Mchc no statistical difference was found among groups although DENA (35.27 d/dL) and TQ+DENA $(35.37 \mathrm{~g} / \mathrm{dL})$ groups were higher than control $(33.90 \mathrm{~g} / \mathrm{dL})$ and TQ $(34.40 \mathrm{~g} / \mathrm{dL})$ groups.

Erythrocyte fragility of TQ group was found higher at 0.4 and $0.5 \% \mathrm{NaCl}$ conditions compared to other groups without statistical significance $(p>0.05)$ (Fig. 1).

\section{Discussion}

Thymoquinone which is a potent anti-inflammatory and anti-tumoral agent and found in seeds of NS was tested in diethylnitrosamine administered rats for its potential protective effect on hematological parameters and erythrocyte fragility. Augmentation in erythrocyte, hemoglobin and hematocrit count due to DENA administration and an insignificant reversal impact of TQ administration were observed.

Erythrocyte fragility results present no significant alteration due to DENA or TQ administration. A slight increase in 0.4 and $0.5 \% \mathrm{NaCl}$ concentrations was observed due to TQ administration however this increase did not reach statistical significance. These results state no apparent impact of those applied chemicals on membrane stability of erythrocytes. Although TQ is stimulating suicidal death of tumor cells and exert its anti-carcinogenic activity by this activity, similar to nucleated cells, erythrocytes were also shown to experience suicidal death or eryptosis due to TQ exposure [35]. Although we observed no significant alteration in erythrocyte fragility due to TQ administration, almost in all $\mathrm{NaCl}$ concentrations hemolysis percentage was highest in TQ applied group. Reason of insignificant results may be due to relatively short administration period (5 days). Longer exposure to TQ may then cause 
significant increase in erythrocyte hemolysis. Although NS is a well-known medicinal plant due to its various health benefit, this active ingredient of NS may show adverse effects on erythrocyte membrane stability and erythrocyte viability at those applied doses. In a study crude extract of NS administered at high doses showed potent anti-hemolytic activity in osmotic fragility test [36]. Preincubation of erythrocytes with NS was reported to show a protection against increased osmotic fragility caused by $\mathrm{H}_{2} \mathrm{O}_{2}$ [37]. Similarly NS aqueous seed extracts showed a protective role in erythrocyte fragility in alloxan induced diabetic rats [38]. This reveals a protective effect of NS on erythrocyte membrane. Another ingredient found in this plant may exert this protective activity against osmotic fragility or a synergistic effect can be considered, however, TQ alone at our dosage did not show such a protective effect.

Results of different blood parameters revealed that DENA increased erythrocyte count significantly compared to control. Result of TQ+DENA group was lower compared to DENA group however this decrease was not statistically significant. Therefore it can be concluded that TQ administration possess a slight reversal effect. In a study by Salau et al. [39] $30 \mathrm{mg} / \mathrm{kg}$ DENA once a week on weeks 3 and 4 significantly altered liver MDA, SOD, CAT, GPX, GR levels. However DENA administration did not change red blood cell count, haemoglobin concentration, packed cell volume, mean corpuscular volume, mean corpuscular haemoglobin, mean corpuscular haemoglobin concentration, white blood cell count, lymphocyte count and neutrophil count). This finding is in contrary with our results. A similar pattern was also observed in hematocrit value. DENA group presented the highest hematocrit value among groups. Similar to the result observed in erythrocyte count, TQ administration slightly reversed the impact of DENA but without statistical significance. In a study by Zaoui et al. [40] administration of $1 \mathrm{ml} / \mathrm{kg} /$ day NS seed fixed oil for 12 weeks showed an increase in hematocrit values. However in our study TQ exerted no such effect. This finding suggests a differential activity of whole plant extract and its active ingredient TQ. Another blood parameter, the hemoglobin value, was found higher in DENA administered group significantly compared to control and TQ groups. In a study by Gnanaraja and Prakash [21] methanolic extract of Tephrosia purpurea was shown to ameliorate alterations caused by DENA in hemoglobin in mice.

DENA is known for its potent hazardous impact on liver, gastrointestinal system, blood chemistry parameters and oxidative stress. Various studies exist to test protective effect of different biologically active molecule against impact of DENA administration. Pradeep et al. [15] administered DENA as single dose and it caused hepatotoxicity and oxidative stress. In their study Cassia fistula resulted in the reversal of most of the parameters studied markers of hepatotoxicity and oxidative stress. In another study by Atakisi et al. [41] administration of omega 3 fatty acids $(0.4 \mathrm{~g} / \mathrm{kg}$ for 7 days) was shown to exert protective effect against DENA caused alterations in liver enzyme parameters, NO production and uric acid levels via its free radical scavenging activity. Evaluation of similar studies suggested reversal of hazardous impact caused by DENA depending on antioxidant and liver protective effect of tested biological molecules.

This study, designed to test protective effect of TQ in DENA administered rats, show a slight ameliorative effect of TQ in concomitant administration with DENA. Longer administration schemes may yield a more protective effect of TQ in such hematological parameters whereas may present significant increase in erythrocyte osmotic fragility due to TQ.

\section{References}

[1] Brown JL. N-Nitrosamines. Occup Med 1999;14:839-48.

[2] Sullivan BP, Meyer TJ, Stershic MT, Keefer LK. Acceleration of N-nitrosation reactions by electrophiles. IARC Sci Publ 1991;370-4. 
[3] Reh BD, Fajen JM. Worker exposures to nitrosamines in a rubber vehicle sealing plant. Am Ind Hyg Assoc J 1996;57: 918-23.

[4] Rajewsky MF, Dauber W, Frankenberg H. Liver Carcinogenesis by Diethylnitrosamine in the Rat. Science 1966;152: 83-5.

[5] Velho AV, Hartmann AA, Kruel CDP. Effect of black tea in diethylnitrosamine-induced esophageal carcinogenesis in mice. Acta Cir Bras 2008;23:4.

[6] Park HS, Lee JH, Lee MJ, Lu JN, Go SI, Kang MH, Kim SH, Kim HG, Lee WS, Kim GS, Rye CH, Jung JM, Hong SC, Ko CH. Low Concentration of Diethylnitrosamine Induces Focal Gastric Dysplasia in the Stomach. Cancer Prevention Research 2012;17:69-73.

[7] Bishayee A, Sarkar A, Chatterjee M. Further evidence for chemopreventive potential of $\beta$-carotene against experimental carcinogenesis: Diethylnitrosamine-initiated and phenobarbital-promoted hepatocarcinogenesis is prevented more effectively by $\beta$-carotene than by retinoic acid. Journal of Nutrition and Cancer 2000;37:89-98.

[8] Tatematsu M, Mera Y, Inoue T, Satoh K, Sato K, Ito N. Stable phenotypic expression of glutathione S-transferase placental type and unstable phenotypic expression of gamma-glutamyltransferase in rat liver preneoplastic and neoplastic lesions. Carcinogenesis 1988;9:215-20.

[9] Bansal AK, Bansal M, Soni G, Bhatnagar D. Protective role of Vitamin E pre-treatment on N-nitrosodiethylamine induced oxidative stress in rat liver. Chem Biol Interact 2005;56:101-11.

[10] Hsu PC, Buxton JA, Tu AW, Hill WD, Yu A, Krajden M. Publicly funded pegylated interferon-alpha treatment in British Columbia disparities in treatment patterns for people with hepatitis C. Can J Gastroenterol 2008;22:359-64.

[11] Lemoine A, Azoulay D, Jezequel-Cuer M, Debuire B. Hepatocellular carcinoma. Pathol Biol 1999;47:903-10.

[12] Young KJ, Lee PN. Intervention studies on cancer. Eur J Cancer Prev 1999;8:91-103.

[13] Vesselinovitch SD, Koka M, Mihailovich N. Carcinogenicity of diethylnitrosamine in newborn, infant, and adult mice. J Cancer Res Clin Oncol 1984;108:60.

[14] Ostrowski JL, Ingleton PM, Underwood JCE, Parsons MA. Increased hepatic androgen receptor expression in female rats during diethylnitrosamine liver carcinogenesis. A possible correlation with liver tumor development. Gastroenterology 1988;94:1193-200.

[15] Pradeep K, Mohan CVR, Gobianand K, Karthikeyan S. Protective effect of Cassia fistula Linn. on diethylnitrosamine induced hepatocellular damage and oxidative stress in ethanol pretreated rats. Biol Res 2010;43:113-25.

[16] Hassanen NHM, Ahmed MHM. Protective effect of fish oil and virgin olive oil on diethylnitrosamine toxicity in rats. International Journal of Nutrition and Food Sciences 2015;4:388-96.

[17] Avasilcai L, Slencu BG, Ciobanu C, Cuciureanu R. Effects of sodium selenite administration during diethylnitrosamine intoxication in rats. Seria Ştiinţele Vieţii, 2011;21:275-80.

[18] Gayathri R, Priya DKD, Gunassekaran GR, Sakthisekaran D. Ursolic acid attenuates oxidative stress-mediated hepatocellular carcinoma induction by diethylnitrosamine in male wistar rats. Asian Pacific Journal of Cancer Prevention 2009;10:933-8.

[19] Hassan SK, Mousa AM, Eshak MG, Farrag AH, Badawi AM. Therapeutic and chemopreventive effects of nano curcumin against diethylnitrosamine induced hepatocellular carcinoma in rats. International Journal of Pharmacy and Pharmaceutical Sciences 2014;6:54-62.

[20] Sarkar A, Bishayee A, Chatterjee M. Beta-carotene prevents lipid peroxidation and red blood cell membrane protein damage in experimental hepatocarcinogenesis. Cancer Biochem Biophys 1995;15:111-25.

[21] Gnanaraja R, Prakash V. (2014). Preventive effect of tephrosia purpurea against N,N-diethylnitrosamine induced hepatocellular carcinoma in swiss albino mice. Journal of Biology and Life Science 2014;5:1-9.

[22] Houghton PJ, Zarka R, de las Heras B, Hoult JR. Fixed oil of Nigella sativa and derived thymoquinone inhibit eicosanoid generation in leukocytes and membrane lipid peroxidation. Planta Med 1995;61:33-6.

[23] El Daly ES. Protective effect of cysteine and vitamin E Crocus sativus and Nigella sativa extracts on cisplatin-induced toxicity in rats. J Pharm Belg 1998;53:87-93.

[24] Rogozhin EA, Oshchepkova YI, Odintsova TI, Khadeeva NV, Veshkurova ON, Egorov TA, Grishin EV, Salikhov SI Novel antifungal defensins from Nigella sativa L Seeds. Plant Physiol Biochem 2011;49:131-7.

[25] Ekanem JT, Yusuf OK. Some biochemical and haematological effects of black seed (Nigella sativa) oil on T.bruceiinfected rats. African Journal of Biomedical Research 2008;11:79-85.

[26] Sivaramakrishnan V, Shilpa PN, Praveen Kumar VR, Devaraj NS. Attenuation of N-nitrosodiethylamine-induced hepatocellular carcinogenesis by a novel flavonol-Morin. Chem Biol Interact 2008;171:79-88.

[27] Ramakrishnan G, Raghavendran HR, Vinodhkumar R, Devaki T. Suppression of N- nitrosodiethylamine induced hepatocarcinogenesis by silymarin in rats. Chem Biol Interact 2006;161:104-14.

[28] Kweon S, Park KA, Choi H. Chemopreventive effect of garlic powder diet in diethylnitrosamine-induced rat hepatocarcinogenesis. Life Sci 2003;73:2515-26. 
[29] Yadav AS, Bhatnagar D. Chemo-preventive effect of Star anise in N-nitrosodiethylamine initiated and phenobarbital promoted hepato-carcinogenesis. Chem Biol Interact 2007;169:207-14.

[30] Singh JP, Selvendiran K, Banu SM, Padmavathi R, Sakthisekaran D. Protective role of Apigenin on the status of lipid peroxidation and antioxidant defense against hepatocarcinogenesis in Wistar albino rats. Phytomedicine 2004;11: 309-14.

[31] Barbisan LF, Scolastici C, Miyamoto M, Salvadori DM, Ribeiro LR, Da Eira AF. Camargo Effects of crude extracts of Agaricus blazei on DNA damage and on rat liver carcinogenesis induced by diethylnitrosamine. Genet Mol Res 2003;2:295-308.

[32] Salim LZA, Mohan S, Othman R, Abdelwahab SI, Kamalidehghan B, Sheikh BY, Ibrahim MY. Thymoquinone induces mitochondria-mediated apoptosis in acute lymphoblastic leukaemia in vitro. Molecules 2013;18:11219-40.

[33] Yi T, Gook CS, Yi Z, Pang X, Rodriguez M, Wang Y, Sethi G, Aggarwal B, Liu M. Thymoquinone inhibits tumor angiogenesis and tumor growth through suppressing AKT and extracellular signal-regulated kinase signaling pathways. Molecular Cancer Therapeutics 2008;7:1789-96.

[34] Nithya G, Mani R, Sakthisekaran D. Oral administration of thymoquinone attenuates benzo(a)pyrene induced lung carcinogenesis in male Swiss albino mice. International Journal of Pharmacy and Pharmaceutical Sciences 2014;6:260-3.

[35] Qadri SM, Mahmud H, Föller M, Lang F. Thymoquinone-induced suicidal erythrocyte death. Food and Chemical Toxicology 2009;47:1545-9.

[36] Saad EA, Habib SA. Effect of crude extracts of some medicinal plants on the osmotic stability of human erythrocytes in vitro. The Journal of Free Radicals and Antioxidants 2013;139:265-72.

[37] Suboh SM, Bilto YY, Aburjai TA. Protective effects of selected medicinal plants against protein degradation, lipid peroxidation and deformability loss of oxidatively stressed human erythrocytes. Phytother Res 2004;18:280-4.

[38] Ayinla MT, Soladoye AO, Olayaki LA, Suleiman SO. Effect of aqueous seed extract of Nigella sativa on some haematological values, lipid peroxidation and osmotic fragility changes in Alloxan induced diabetic rats. Tropical Journal of Health Sciences 2010;17:1-4.

[39] Salau AK, Yakubu MT, Oladiji AT. Effects of Aqueous Root Bark Extracts of Anogeissus leiocarpus (DC) Guill \& Perr and Terminalia avicennioides Guill \& Perr on Redox and Haematological Parameters of DiethylnitrosamineAdministered Rats. Iranian Journal of Toxicology 2016;10:21-9.

[40] Zaoui A, Cherrah Y, Alaoui K, Mahassine N, Amarouch H, Hassar M. Effects of Nigella sativa fixed oil on blood homeostasis in rat. Journal of Ethnopharmacology 2002;79:23-6.

[41] Atakisi O, Atakisi E, Ozcan A, Karapehlivan M, Kart A. Protective effect of omega-3 fatty acids on diethylnitrosamine toxicity in rats. Eur Rev Med Pharmacol Sci 2013;17:467-71. 